\title{
Minimizing dust emission during routing operation of rubberwood
}

\begin{abstract}
The study evaluated airborne dust emission $(0.1-10 \mu \mathrm{m})$ during the routing operation of Rubberwood (Hevea brasiliensis) in the furniture industry in South East Asia. It was found that the average chip thickness of $0.1 \mathrm{~mm}$ and wood moisture content of 12-14\% minimized dust emission, while the cutting tool rake angle had little influence on dust emission. The study shows that adverse economic implications due to health hazards posed by airborne dust emissions during wood machining can be reduced by manipulating the average chip thickness and work-piece moisture content.
\end{abstract}

Keyword: Airborne dusts, Chip thickness, Dust emission, Economic implications, Furniture industry, Hevea brasiliensis, Moisture contents, Rubberwood, Southeast Asia, Wood machining, Wood moisture content, Work pieces 